\title{
The drive to taper opioids: mind the evidence, and the ethics
}

\author{
Stefan G. Kertesz $\mathbb{1}^{1,2} \cdot$ Ajay Manhapra ${ }^{3,4,5}$
}

Received: 20 April 2018 / Revised: 5 June 2018 / Accepted: 7 June 2018

(c) International Spinal Cord Society 2018

\begin{abstract}
The high prevalence of pain in patients with spinal cord injury, coupled with a national recalibration of opioid prescribing, presents a challenge. Prescribers may attempt to taper opioids, where observable harms from the prescribed opioid appear to outweigh benefits, a stance endorsed by the 2016 Guideline for Prescribing Opioids for Chronic Pain, issued by the Centers for Disease Control and Prevention. Different considerations apply when clinicians wish to reduce doses in adherent and stable patients, absent their consent. In this perspective piece, we acknowledge the problematic nature of opioids as a treatment. However, forced tapers may destabilize patients and clinical evidence to support forced tapers is lacking. We favor an ethic of informed consent when proposing changes to care involve meaningful risk, and suggest alternative approaches to optimizing safety.
\end{abstract}

The question of how to care for patients who receive opioids at high-dose vexes, many physicians caring for patients with spinal cord injury (SCI). Their prevalence of pain is high, with estimates varying from 44 to $67 \%$ [1], and opioids are commonly used and misused by this patient population [2].

This question has become especially pressing because of an ongoing policy recalibration in response to a tragedy spurred in part by excess prescribing of opioids [3, 4]. That tragedy has forced a reconsideration of the risks and benefits of opioid medications for chronic pain. Their once-vaunted status as an easy option for care of longterm pain has fallen in light of observational correlations suggesting risks not just of poisoning and overdose [5], but new-onset addiction [6], depression [7] and possibly, immune suppression [8]. Where opioids are prescribed, the dose correlates with overdose risk, in most but not all

Stefan G. Kertesz

skertesz@uabmc.edu

1 Birmingham VA Medical Center, Birmingham, AL, USA

2 University of Alabama at Birmingham School of Medicine, Birmingham, AL, USA

3 VA New England Mental Illness Research and Education Center, West Haven, Connecticut, USA

4 Hampton VA Medical Center, Hampton, VA, USA

5 Department of Psychiatry, Yale School of Medicine, New Haven, CT, USA correlational analyses [9-11]. Given those findings, might it not be prudent for any doctor to insist upon a slow dose reduction, with or without the consent of the patient, targeting a dose of perhaps 90 morphine milligram equivalents or less? In this opinion piece, we propose that this course of action can be attempted in a voluntary patient. It may also be considered in a patient who is clearly suffering documented harm exceeding observable benefits from their medication regimen. However, data to justify forced dose tapering in the otherwise stable patient is weak, and the 2016 Guideline of the Centers for Disease Control and Prevention (CDC) chose not to endorse this course of action [12]. Forced tapers, slow or fast, can harm previously stable patients [13], while crossing ethical lines doctors normally respect. Advocates for this approach have stepped ahead of data, when available science dictates a more tempered approach.

To consider the pros and cons of nonconsensual weaning of opioids, it may help to consider why opioids are often started, the challenges that they pose for some patients, and the challenges associated with stopping.

It may seem a truism that opioids are started and continued for the management of moderate-to-severe pain, but their benefit is debatable. Their trial record involves benefit when compared to placebo in studies that are typically of short duration [14]. For patients with chronic musculoskeletal pain randomly assigned in a 1-year trial led by Dr. Erin Krebs [15], opioid monotherapy did not outperform a carefully staged sequence of nonopioid 
treatments (culminating, for a few, in a low-potency opioid). To say that they performed comparably to nonopioid treatments does not mean opioids are ineffective. But neither does it recommend them as an obvious next step for the average patient with joint pain who, like those recruited to the trial by Krebs et al., qualified for trial entry after reporting that ibuprofen or similar medications seemed insufficient. Clinicians will have to judge for themselves about how best to apply this trial's findings to patients with SCI, whose pain syndromes may prove more challenging.

One reason that opioids fail to do well in trail comparisons to other treatments is that $25-60 \%$ of patients find them intolerable [16]. If over half can not tolerate a treatment, and some develop addiction (0.7-6\% in data cited by the CDC's Guideline $[6,12])$, that leaves only a modest percentage in whom to look for evidence of benefit. But for that group, is there a benefit? Each of us could venture an opinion and find a way to defend it. Some may argue that tolerance (reduced effect at constant dose) and dependence (patterned behavior and adverse effects with discontinuation) defines a situation where patients cannot be trusted to know if they are "doing well" on opioids [17]. Hyperalgesia sometimes features in these arguments, too. But prospective trial data suggest that hyperalgesia is not a regular event in humans on longterm opioids for pain [18].

For a treatment that is rarely first or second line, we note that some patients with chronic noncancer pain obtain meaningful and salient relief from them. We are hesitant to withhold this treatment in situations where we see no better alternatives, if the risks can be mitigated [19]. Pain is a brain-generated response to a stimulus; it involves the fusion of a threatening sensation, affect, and cognition. It is, for most of us, a formidable event. To quote Dr. Albert Schweitzer, "Pain is a more terrible lord of mankind than even death itself [20].'

To the extent that opioids seem to help, their impact likely involves action at multiple levels. Antinociceptive benefits are combined with effects on brain centers relevant to affect and reward. This combination confers relief. But, unavoidably, this same combination of effects, precisely what makes opioids effective, also makes opioids subject to dependence. One of us has termed this "the boon and the curse" of opioids [13]. Estimates for the emergence of aberrant behaviors vary among sample and study designs, with rates reported of between 3 [21] and 17\% [22]. Conversely, $25-33 \%$ of people treated with opioids seem to do reasonably at stable dose [23], although over $50 \%$ find the same medicines intolerable.

A challenge often arises for a physician who inherits a patient and must decide whether to continue doses started by others. Were all factors equal, one could argue that lower doses are always better than higher. Why not tell the patient that there has been a historical overestimation of opioids' value, and force a dose reduction, as so many insurers and regulators are keen to see us do?

To approach this question, we must ask "what problem are we trying to fix, and what data support our approach?" Patients are not all the same. We might divide them crudely enough into 2 groups: less stable and more stable.

Many prescribers see problems in their unstable opioidreceiving patients: lack of activity, volatile affect, excessive sedation, loss of coordination, and more. These reflect a neuropsychological collision of the drivers of chronic pain, dependence, psychological vulnerabilities, and polypharmacy. Sedation and grogginess may improve with taper, but taper makes some patients worse, not better. Even with a plausible argument for taper, the results in practice may include harm [24-26]. In one large trial of patients diagnosed with prescription opioid use disorder who volunteered for taper, the failure rate was $91 \%$ [27]. There is no reason to think every patient with pain is the same as patients in that trial. However, the $91 \%$ failure rate, for an intervention now incentivized by payers, quality metric agencies, and governments, signals an issue of concern with respect to their aggressive push to taper all patients at higher dose.

For the less stable patients, alternative care approaches may include monitored opioid continuation (coupled with expansion of care to address psychological challenges) or a switch to buprenorphine.

A more vexing ethical challenge has emerged recently: taper undertaken in otherwise stable, functional patients, against their will, either in the name of helping them or as a result of insurer policies. The evidence to support this practice is weak, and risks of harm include rupture of the care relationship. A recent review reported that while small, low-quality studies seemed to support opioid dose reduction in voluntary patients, no studies addressed mandatory taper [28]. It is this lack of evidence that led the CDC's Guideline experts to withhold endorsing it. Today there are academic studies [25] and lay reports [29] in which patients have become suicidal in reaction to this practice. The frequency of such events is unknown.

With otherwise stable and functional patients, we see no wisdom in bypassing the ethical matter of patient consent. Some physicians will assert that slow tapers prevent bad outcomes. This argument, however, confuses two distinct syndromes, and the rate of taper is relevant only to one of them. Acute physiologic withdrawal can indeed be averted with slower tapers. However, for some patients, there will be a prolonged abstinence syndrome involving changes to emotion and affect [13]. No one has proven that slower tapers avert this latter outcome. We have seen patients harmed grievously by such practices, 
and we have reported them. Finally, there is the matter of relief being withdrawn, at least as patients see it. Taper is not a pain treatment.

None of this makes the situation any easier for the physician inheriting patients at high dose. Our suggestion is to tabulate all known risks affecting patients and look for ways to mitigate them. In large studies, much opioid risk is associated not with dose, but with polypharmacy, including tricyclic antidepressants, gabapentin, and benzodiazepines [19]. Risk is also correlated with psychological distress and with mental health disorders, which can be addressed. As prescribers, we confess to having used our leverage to get patients into more comprehensive health care, often including nurses, psychologists, and therapists. Terminating opioids is not the centerpiece of that approach to safety.

Views expressed in this article are those of the authors and do not represent positions or views of the US Department of Veterans Affairs or any other agency of the United States federal government.

\section{Compliance with ethical standards}

Conflict of interest Dr. Kertesz reports prior ownership of stock in Merck and Abbot, not exceeding 3\% of his assets. These were sold in December 2017. He has no other history of honoraria, payments, commercial relationships, consultancies, gifts or any other financial interaction, involving the pharmaceutical industry. Dr. Manhapra has no disclosures to make.

\section{References}

1. Gorp S, Kessels AG, Joosten EA, Kleef M, Patijn J. Pain prevalence and its determinants after spinal cord injury: a systematic review. Eur J Pain. 2015;19:5-14.

2. Clark JM, Cao Y, Krause JS. Risk of pain medication misuse after spinal cord injury: the role of substance use, personality, and depression. J Pain. 2017;18:166-77.

3. Van Zee A. The promotion and marketing of oxycontin: commercial triumph, public health tragedy. Am J Public Health. 2009;99:221-7.

4. Kertesz SG. Turning the tide or riptide? The changing opioid epidemic. Subst Abus. 2016;38:1-6.

5. Bohnert ASB, Valenstein M, Bair MJ, Ganoczy D, McCarthy JF, Ilgen MA, et al. Association between opioid prescribing patterns and opioid overdose-related deaths. J Am Med Assoc. 2011;305:1315-21.

6. Edlund MJ, Martin BC, Russo JE, DeVries A, Braden JB, Sullivan MD. The role of opioid prescription in incident opioid abuse and dependence among individuals with chronic noncancer pain: the role of opioid prescription. Clin J Pain. 2014;30:557-64.

7. Salas J, Scherrer JF, Schneider FD, Sullivan MD, Bucholz KK, Burroughs T, et al. New-onset depression following stable, slow, and rapid rate of prescription opioid dose escalation. Pain. 2017;158:306-12.

8. Wiese AD, Griffin MR, Schaffner W, Stein CM, Greevy RA, Mitchel EF Jr, et al. Opioid analgesic use and risk for invasive pneumococcal diseases: a nested case-control study. Ann Intern Med. 2018;168:396-404.
9. Glanz JM, Narwaney KJ, Mueller SR, Gardner EM, Calcaterra $\mathrm{SL}, \mathrm{Xu} \mathrm{S}$, et al. Prediction model for two-year risk of opioid overdose among patients prescribed chronic opioid therapy. J Gen Intern Med. 2018, https://doi.org/10.1007/s11606-017-4288-3.

10. Bohnert AS, Logan JE, Ganoczy D, Dowell D. A detailed exploration into the association of prescribed opioid dosage and overdose deaths among patients with chronic pain. Med Care. 2016;54:435-41.

11. Gomes T, Mamdani MM, Dhalla IA, Paterson JM, Juurlink DN. Opioid dose and drug-related mortality in patients with nonmalignant pain. Arch Intern Med. 2011;171:686-91.

12. Dowell D, Haegerich TM, Chou R. CDC guideline for prescribing opioids for chronic pain - United States, 2016. Morb Mortal Wkly Rep. 2016;65:1-49.

13. Manhapra A, Arias AJ, Ballantyne JC. The conundrum of opioid tapering in long-term opioid therapy for chronic pain: a commentary. Subst Abus. 2017; https://doi.org/10.1080/08897077. 2017.1381663.

14. Chou R, Turner JA, Devine EB, Hansen RN, Sullivan SD, Blazina I, et al. The effectiveness and risks of long-term opioid therapy for chronic pain: a systematic review for a National Institutes of Health Pathways to Prevention Workshop. Ann Intern Med. 2015;162:276-86.

15. Krebs EE, Gravely A, Nugent S, Jensen AC, DeRonne B, Goldsmith ES, et al. Effect of opioid vs nonopioid medications on painrelated function in patients with chronic back pain or hip or knee osteoarthritis pain: the SPACE Randomized Clinical Trial. J Am Med Assoc. 2018;319:872-82.

16. Stannard C, Mooore A. Traditional opioids for chronic noncancer pain: untidy, unsatisfactory, and probably unsuitable. Evid Cochrane Ser. 2016, http://www.evidentlycochrane.net/opioidschronic-non-cancer-pain/, Accessed June 14, 2018.

17. Juurlink DN. Rethinking "doing well” on chronic opioid therapy. CMAJ. 2017;189:E1222-E3.

18. Chu LF, D'Arcy N, Brady C, Zamora AK, Young CA, Kim JE, et al. Analgesic tolerance without demonstrable opioid-induced hyperalgesia: a double-blinded, randomized, placebo-controlled trial of sustained-release morphine for treatment of chronic nonradicular low-back pain. Pain. 2012;153:1583-92.

19. Oliva EM, Bowe T, Tavakoli S, Martins S, Lewis ET, Paik M, et al. Development and applications of the Veterans Health Administration's Stratification Tool for Opioid Risk Mitigation (STORM) to improve opioid safety and prevent overdose and suicide. Psychol Serv. 2017;14:34-49.

20. Schweitzer A. A l'orée de la forêt vierge. Lausanne: Édition la Concorde; 1923.

21. Cheatle MD, Gallagher RM, O'Brien CP. Low risk of producing an opioid use disorder in primary care by prescribing opioids to prescreened patients with chronic noncancer pain. Pain Med. 2017;19:764-73.

22. Banta-Green CJ, Merrill JO, Doyle SR, Boudreau DM, Calsyn DA. Opioid use behaviors, mental health and pain--development of a typology of chronic pain patients. Drug Alcohol Depend. 2009;104:34-42.

23. Häuser W, Bock F, Engeser P, Tölle T, Willweber-Strumpf A, Petzke F. Long-term opioid use in noncancer pain. Dtsch Ärzteblatt Int. 2014;111:732-40.

24. Weeks WB. Hailey. J Am Med Assoc. 2016;316:1975-6.

25. Demidenko MI, Dobscha SK, Morasco BJ, Meath THA, Ilgen MA, Lovejoy TI. Suicidal ideation and suicidal self-directed violence following clinician-initiated prescription opioid discontinuation among long-term opioid users. Gen Hosp Psychiatry. 2017;47:29-35.

26. Kertesz SG, Satel SS. Some People Still Need Opioids. http://www.slate.com/articles/health_and_science/medical_exa 
miner/2017/08/cutting_down_on_opioids_has_made_life_misera ble_for_chronic_pain_patients.html, Accessed June 14, 2017.

27. Weiss RD, Potter JS, Fiellin DA, Byrne M, Connery HS, Dickinson W, et al. Adjunctive counseling during brief and extended buprenorphine-naloxone treatment for prescription opioid dependence: a 2-phase randomized controlled trial. Arch Gen Psychiatry. 2011;68:1238-46.
28. Frank JW, Lovejoy TI, Becker WC, Morasco BJ, Koenig CJ, Hoffecker L, et al. Patient outcomes in dose reduction or discontinuation of long-term opioid therapy: a systematic review. Ann Intern Med. 2017;167:181-91.

29. Kertesz SG, Satel SL, Gordon AJ. Opioid prescription control: when the corrective goes too far. Health Affairs; 2018. 